\title{
Article
}

\section{Strategic Account Management as a value co-creation selling model in the Pharmaceutical Industry}

\author{
Pillon, Francois and Hadjielias, Elias
}

Available at http://clok.uclan.ac.uk/16490/

Pillon, Francois and Hadjielias, Elias (2017) Strategic Account Management as a value co-creation selling model in the Pharmaceutical Industry. Journal of Business and Industrial Marketing, 32 (2). pp. 310-325. ISSN 0885-8624

It is advisable to refer to the publisher's version if you intend to cite from the work. http://dx.doi.org/10.1108/JBIM-05-2015-0100

For more information about UCLan's research in this area go to http://www.uclan.ac.uk/researchgroups/ and search for < name of research Group>.

For information about Research generally at UCLan please go to http://www.uclan.ac.uk/research/

All outputs in CLoK are protected by Intellectual Property Rights law, including Copyright law. Copyright, IPR and Moral Rights for the works on this site are retained by the individual authors and/or other copyright owners. Terms and conditions for use of this material are defined in the policies page.

\section{CLoK}

Central Lancashire online Knowledge www.clok.uclan.ac.uk

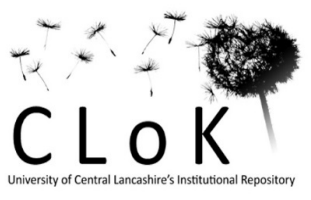





\title{
Strategic Account Management as a value co-creation selling
}

\section{model in the Pharmaceutical Industry}

\author{
Francois Pilon \\ Pharmascience Inc \\ 6111, Royalmount Avenue, Montréal, Québec H4P 2T4 Canada \\ pilon.francois@,hotmail.com
}

Elias Hadjielias ${ }^{1}$

School of Business and Management

University of Central Lancashire

12-14 University Avenue, Pyla 7080 Larnaka, Cyprus

Tel: +357 24694057, Email: ehadjielias@uclan.ac.uk

\footnotetext{
${ }^{1}$ Corresponding author
} 


\section{Strategic Account Management as a value co-creation selling model} in the Pharmaceutical Industry

21

22

23

24

25

26

27

28

29

30

31

32

33

34

35

36

37

38

39

40

41

42

43

44

45

46

47

48

49

50

51

52

53

54

55

56

57

58

59

60 


\begin{abstract}
Purpose: This study explores the dynamics enabling Strategic Account Management (SAM) to function as a value co-creation selling model in the pharmaceutical industry.

Methodology: Using an inductive qualitative research design, data are collected within eleven industry customers in Canada. This work focuses on hospitals as strategic accounts of pharmaceutical companies, exploring SAM value co-creation in the 'hospital-pharmaceutical company' relationship.
\end{abstract}

Findings: The findings suggest the presence of two key dimensions that can enable a value co-creation SAM model in the hospital-pharmaceutical relationship: 'customer-tailored value-added initiatives' and 'relationship enhancers'. Customer-tailored value-added initiatives explain the activities that are central to the hospital-pharmaceutical company relationship and can lead to the provision of value-added that is unique to the hospital. Relationship enhancers explain the activities that can help strengthen hospitalpharmaceutical company relations in the pursuit of enhanced value-added interactions between the two parties. The research demonstrates a cyclical relationship between 'customer-tailored value-added initiatives' and 'relationship enhancers' leading to value co-creation through a SAM model.

Practical implications: The study informs pharmaceutical industry practitioners on how to improve their value proposition through new, more sustainable selling practices. It offers information in implementing a value co-creation SAM model, which can enable pharmaceutical companies to sustain long lasting value added relationships with key accounts such as hospitals.

Originality/value: The study contributes to the field of strategic account management by conceptualizing SAM as a value co-creation system. It introduces new knowledge in pharmaceutical marketing by offering empirical insight on the applicability and use of SAM in the hospital-pharmaceutical company dyad. 


\section{Introduction}

Over the past decade, the pharmaceutical market has evolved and a direct consequence has been to challenge the sustainability of the model companies employ to market products and services and serve client needs (Patterson, 2008; Payne et al., 2015; Wenzel et al., 2014). The current selling model used by pharmaceutical companies is primarily product-centered. Efforts are directed in creating products and services and then pushing generic offerings to clients (Wenzel et al., 2014) via means such as detailing, sampling, direct-to-consumer advertising, and journal advertising (Hilsenrath, 2011). This has a firm- and product-centric view of value and the process of value creation (Matthing et al., 2004; Johannessen and Olsen, 2010; Prahalad and Ramaswamy, 2004; Vargo et al., 2008), which is increasingly becoming inflexible in accommodating changes in line with the rapidly changing environmental conditions in the pharmaceutical industry: an increasingly competitive environment and especially the changing customer needs and higher client expectations (Klein, 2008; Patterson, 2008; Payne et al., 2015; Wenzel et al., 2014).

Accordingly, in the current environment, drug development and commercialization is a long, costly, and risky endeavor. The cost of bringing a drug from concept to market has increased significantly and in 2014 was estimated to be \$2.6 billion, up from \$802 million back in 2003 (TUFTS, 2014). At the same time, it also takes ten to fourteen years to bring a single drug from concept to market (DiMasi and Grabowski, 2007; Patterson, 2008; Potts et al., 2015), which means that a 20-year patent provides limited time to recoup R\&D investment (Patterson, 2008; Wenzel et al., 2014). As a result, pharmaceutical companies are financially challenged to make sales the success they once were in the past: it costs more and is riskier than ever to bring a new product to market, and there is less time to recoup the money (DiMasi and Grabowski, 2007; 
Patterson, 2008; Payne et al., 2015; Wenzel et al., 2014). Consequently, the model utilized to commercialize and sell products needs to change to reflect better the contemporaneous realities of pharmaceutical companies. To that end, it is increasingly acknowledged that the selling model needs to delve beyond product-centered strategies towards approaches that can offer more flexibility in meeting changing customer needs and ones that can establish long term productive relationships with key customers (Wenzel et al., 2014). Research on customer-centric selling models, such as a Strategic Account Management model (SAM) (Gosselin and Heene, 2003; Gosselin and Bauwen, 2006), is critical in acknowledging alternative means through which pharmaceutical products and services can be marketed. The present study focuses on Strategic Account Management as a client-centred approach to servicing the client. SAM is understood as a selling model that can help an organisation to delve beyond value embedded in predefined output (Gosselin and Heene, 2003; Gosselin and Bauwen, 2006; Vargo et al., 2008).

It is generally agreed, that Strategic Account Management (SAM) reflects a set of organisational practices directed towards the management of relationships with strategically important customers (i.e. strategic accounts) (Miller et al., 1992; Storbacka, 2012). Organisational practices underpinning SAM can, indeed, vary, having as an ultimate goal to optimise the satisfaction of key clients' needs and expectations (Gosselin and Bauwen, 2006; Payne et al., 2008; Storbacka, 2012). Despite the presence of diverse evidence and insight on the content and process of SAM (Gosselin and Bauwen, 2006), the present study builds on understandings that link strategic account management with "value creation" (Anderson, 1995; Gosselin and Bauwen, 2006; Gosselin and Heene, 2003; Vargo and Lusch, 2008). Value creation refers to client perceptions of 'use value' and 'exchange value'. According to Bowman and Ambrosini (2000), value creation is shaped only if customers perceive desirable quality or 
benefits in products/services in relation to their needs and they are willing to pay an amount to enjoy this value (Bowman and Ambrosini, 2000; Lepak et al., 2007). Specifically, the present article moves a step further to embrace an understanding of value creation as "co-creation" (Prahalad and Ramaswamy, 2004; Lee et al., 2012). This is an understanding of value creation as a process where the interaction between the organisation and the client is becoming the locus of value creation (Prahalad and Ramaswamy, 2004) and engages organisation and client(s) in collaborative and dialogic processes leading to co-creation (Lee et al., 2012). This conceptualisation of strategic account management, understands SAM as a system that locks a seller in a continuous relationship with "key" customers, where higher client engagement allows better understanding of customer needs. This way suppliers become more capable in creating and tailoring desirable products \& services that the clients are willing to purchase (Homburg et al., 2002; McDonald et al., 1997; Piercy, 2009; Vargo and Lusch, 2008). In this sense, long term productive relationships with strategically important customers are ensured through efforts directed towards the co-creation and delivery of ongoing value to these customers (Berghman et al., 2006; Cannon and Perreault, 1999; Gosselin and Bauwen, 2006; McDonald et al., 1996, 1997). Hence, the present article treats "value co-creation" as an overarching concept while attempting to understand what can make SAM a value-co creation, and thus a more clientcentred, selling model in the pharmaceutical industry.

From an organizational point of view, applying a SAM model is not a process to be taken lightly, as it is not possible to develop a "one-size-fits-all" structure applicable to all situations; hence, companies must comprehend their unique circumstances and dynamics leading to value co-creation and client value added in order to understand the essence and form of their respective account management systems (Georges and Eggert, 2008). Literature on the topic of SAM, 
though conveying the benefits that pharmaceutical companies can have from its use, offers insufficient insights on what can make SAM a value co-creation mechanism and thus a valuable selling model in this industry. As such, the key research question driving this research is the following:

RQ: "What dynamics are essential for SAM to function as a value co-creation selling model in the pharmaceutical industry?"

'Dynamics' in the context of the present study, is understood to denote the conditions and forces which can stimulate development within a system (Lewin, 1945). In this sense, the present work is set to investigate the developmental conditions and forces that can allow SAM to become and function as a value co-creation system. The parameters of this study are limited to the large branded pharmaceutical industry (excluding generic manufacturers) in the Canadian marketplace.

In line with previous work, this article focuses on hospitals as strategic accounts of pharmaceutical companies (Wartenberg and Gores, 2008), exploring SAM value co-creation dynamics in the context of the hospital-pharmaceutical company relationship. The next section offers a review of literature around Strategic Account Management and its relation to value creation and the pharmaceutical industry, followed by a description of the research methods employed. The remaining sections offer an analysis and discussion of the data collected from various hospitals in Canada, as well as the conclusions, contributions, and implications from the study.

\section{Literature review}




\subsection{Strategic Account Management (SAM)}

Strategic Account Management (SAM) involves a sequence of organisational practices that allow a business to establish fruitful long-term relationships with strategically important customers (Miller et al., 1992; Storbacka, 2012). Early work focused on 'key account management' in efforts to stress the importance of establishing close relations with the few customers which are vital to an organisation' existence (McDonald, 1996, 1997). McDonald (1997) defined key account management 'an approach adopted by companies aimed at building a portfolio of loyal accounts by offering them, on a continuing basis, a product/service package tailored to their individual needs'. Subsequent research, progressively established the notion of 'Strategic Account Management' as a means to emphasise the strategic importance of key account management (Al-Husan and Brennan, 2009; Gosselin and Bauwen, 2006; Gosselin and Heene, 2005). 'Strategic Account Management' (SAM) involves pro-active approaches and sufficient planning behind the management of relationships with key customers, as opposed to reactive moves resulting from competitive practices or changing customer demands. This way, SAM becomes a strategic tool and can contribute to an organisation's unique selling position and efforts to establish a competitive advantage (Gosselin and Heene, 2005; Ivens and Pardo, 2007; Pardo et al., 2006).

SAM, usually involves a business-to-business relationship, where relevant strategic account managers employed at a selling company are assigned to serve and interact with particular business clients (Gosselin and Heene, 2005 McDonald, 1996, 1997). Strategic account managers play a critical mediating role in a business' efforts to establish long-lasting relations with strategically important customers: they represent the selling company's capabilities to the buying 
company and the buying company's needs to the selling company (McDonald, 1996). Empirical insight on the role of strategic account managers, suggests that these individuals fulfill the role of an enabler or promoter of an existing supplier-customer relationship (Bacon, 1999). Their task is also about minimizing the friction within the relationship and optimizing the fit between the supplier's value offer and customer's needs (Weitz and Bradford, 1999).

Interestingly, Gosselin and Bauwen (2006) identified a number of different sources of confusion in the comprehension of strategic account management, and argued that a company's understanding of the differences will contribute to the enhancement of their capabilities to create competitive advantages (based on the creation of customer value). The most important and relevant source of confusion posed was the following: Is it possible to design and implement a single best strategic account management organisational structure, applicable to most types of companies and customers and independent of the complexities of the market (Gosselin and Bauwen, 2006)? The simple answer is no, based on the fundamental organizational theory, the congruency principle (Donaldson, 2001; Mackenzie, 2003; Miles and Snow, 1994), which denotes that it is impossible to design a universal and single best strategy, applicable to all possible situations (Gosselin and Bauwen, 2006). The take-away message from their research is that an account can only be categorized as "strategic" if both the customer is open to a relationship and the supplier has the ability to develop the competencies required to making the relationship work. They argue that this concept is integral to the establishment of a SAM model in any industry, and pertinent to this research.

Ojasalo (2001) proposed certain characteristics to describe the general nature and essence of the SAM approach (see table 1). These findings allow recognizing essential elements to Strategic Account Management: the SAM model is based on long term relationships with selected clients, 
it is established mostly in business-to-business markets, and finally, it is critical for fulfilling a business' profitability and shareholder value goals (Ojasalo, 2001). These elements have been considered in the context of the present paper to establish the profile of customer relationships sought to research for gaining insight on the applicability and use of SAM in the Pharmaceutical industry (more details on the research approach is offered in the Methodology section).

\section{Insert Table 1}

Studies around SAM offer diverse understanding on the conditions and dynamics leading to SAM implementation and functioning within organisations. Ojasalo (2001) proposed that SAM implementation and functioning consists of four basic elements: (1) identifying the key accounts through a number segmentation variables - criticality, quantity, replaceability, slack, (2) analyzing the account on levels such as basic characteristics, relationship history, the level commitment to the relationship, goal congruence of the parties, and switching costs, (3) selecting suitable strategies based on the power positions of the seller and the account, and finally, (4) continuously developing and customizing operational-level capabilities to enhance the relationship on levels such as products \& services, organizational structure, information exchange, and personnel allocated to the account. ALHussan et al. (2014), in turn, identified a number of environmental-specific factors that are likely to affect SAM implementation, including the intensity of competition and ownership structure; product and customer complexity; Western influences (education, training, experience, expatriation); and institutional and cultural influences. Abratt and Kelly (2002) shed light on a different set of factors including knowledge and understanding of the key account customer's business; proper implementation and understanding of the SAM program; commitment to the SAM program; suitability of the key account manager; and the level of trust between supplier and customer. Workman et al. (2003), 
in turn, explain that SAM success depends on SAM team esprit de corps, access to marketing and sales resources, activity intensity and proactiveness, and top management involvement in SAM.

Despite the exploration of dynamics underpinning SAM implementation and functioning, it is increasingly understood that convergence into a common framework underpinning SAM is not possible. This is because the context has a strong influence on SAM implementation and this practice may be seen and applied differently in different companies, industries, and countries (ALHussan et al., 2014). Acknowledging these limitations, the present paper offers fresh insight on SAM implementation and functioning from contexts in which SAM is relatively under researched. This is the pharmaceutical industry in the Canadian economy.

Further, while there is interest in researching and discussing the critical prerequisites of SAM implementation and functioning, the majority of previous work treats SAM as a supplier/sellerdriven approach (Gosselin and Bauwen, 2006; Guenzi et al., 2009; Sullivan et al., 2012), underpinned by a firm-centric view of value creation (Matthing et al., 2004; Johannessen and Olsen, 2010; Prahalad and Ramaswamy, 2004; Vargo et al., 2008). More recent work presents SAM as a means to co-create value with the customer. If SAM is directed towards higher client engagement and co-ownership of the process leading to value creation, then this can help strengthen the quality of and value added from supplier-customer interactions (Lee et al., 2012; Prahalad and Ramaswamy, 2004). The next part sheds light on SAM as a value co-creation approach, and sets the scene for the focus of this paper (i.e. the dynamics that can allow SAM to function as a value co-creation selling model in the pharmaceutical industry).

\subsection{Strategic Account Management \& Value Creation}


Though limited, previous research has explored the links between strategic account management and value creation (Gosselin and Bauwen, 2006; Gosselin and Heene, 2003; Vargo and Lusch, 2008). Value creation is understood as an outcome of both 'use value' and 'exchange value' (Lepak et al., 2007). In this sense, value creation is shaped only if customers perceive desirable quality or benefits in products/services in relation to their needs and they are willing to pay and amount to enjoy this value (Bowman and Ambrosini, 2000; Lepak et al., 2007). This conceptualisation of strategic account management, looks into SAM as a system that locks a seller in a relationship with "key" customers to allow thorough understanding of customer needs with the view to create and tailor desirable products \& services that the clients are willing to pay to enjoy (Homburg et al., 2002; McDonald et al., 1997; Piercy, 2009; Vargo and Lusch, 2008). This way, long term productive relationships with strategically important customers are ensured through efforts directed towards the creation and delivery of ongoing value to these customers (Berghman et al., 2006; Cannon and Perreault, 1999; Gosselin and Bauwen, 2006; McDonald et al., 1996, 1997). According to Gosselin and Bauwen, (2006), SAM is a system for creating and maintaining customer value with important customers and thus creating a competitive advantage based on value creation. Since SAM allows close customer-supplier collaborative relationships, it can make the focus on customer value more evident (Anderson, 1995; Anderson and Narus, 1990; Gosselin and Bauwen, 2006).

A recent extension on value creation refers to the co-creation of value between a company and a client (Ramaswamy, 2011). 'Value co-creation' is 'the process by which mutual value is expanded together" (Ramaswamy, 2011, p. 195). According to Prahalad (2004), value cocreation allows "moving away from the old industry model that sees value as created from goods and services to a new model where value is created by experiences"(p. 172). Value co-creation is 
increasingly understood to reflect the future of value creation in organisations (Lee et al., 2012; Vargo et al., 2008). It establishes a new model where the interaction between the organisation and the client is becoming the locus of value creation (Prahalad and Ramaswamy, 2004). Thus, value co-creation reflects even a more customer-driven perspective, which can help shape more meaningful experiences for the customers since it allows them to co-create with a firm the products and/or services that they purchase (Prahalad, 2004; Prahalad and Ramaswamy, 2004).

Therefore, given the embeddedness of SAM in close customer-supplier relations, strategic account management may be approached and promoted as a value co-creation model, which can allow better flexibility in meeting complex and even individualistic customer needs and in establishing relevant competitive advantages through customer experience maximisation (Wenzel et al., 2014). SAM, in this sense, becomes a dialogic processes leading to co-creation (Lee et al., 2012); interactions with clients acquire more centrality and organisational practices focus on the co-creation of products, services, and/or experiences in line with each client's peculiar circumstances (Lee et al., 2012; Prahalad and Ramaswamy, 2004).

The present work focuses on the pharmaceutical industry which is a manufacturing and product driven sector, and a context where products and services are often shaped and pushed to customers (Wenzel et al., 2014). Value creation as co-creation could be a means through which pharmaceutical companies could improve the satisfaction and experience of the customer and, therefore, establish sustainable competitive advantages. The section that follows reviews literature regarding the existing drug selling model of pharmaceutical companies. It also discusses previous work exploring SAM within the pharmaceutical sector, with the view to set the scene on the phenomenon that this study is set to investigate; i.e. the dynamics that are 
essential for SAM to function as a value co-creation selling model in the pharmaceutical industry.

\subsection{SAM in the Pharmaceutical industry: Towards client driven and value added relations with customers}

\section{The traditional approach to sales}

In the pharmaceutical sector price is not the primary focus of firm efforts to commercialise new drugs, but rather the unique qualities of the product, the better health outcomes, or the optimal convenience or agreeable treatment (Hilsenrath, 2011). In recent years, the pharmaceutical selling model has relied primarily on four approaches: detailing, providing samples, direct-to-consumer (DTC) advertising, and journal advertising (Hilsenrath, 2011). Pharmaceutical detailing utilizes representatives to personally inform and promote products to physicians (Montoya et al., 2010; Rubin, 2004), and is the only component of the selling model which operates through face-to-face interactions with the customer. Given that the concept of Strategic Account Management is built on the same foundation of face-to-face relational interactions (Ivens and Pardo, 2007; Pardo et al., 2006), additional information will be explored specifically on detailing.

Detailing in pharmaceutical industry involves the process of communicating the pharmaceutical product and its benefits to health care professionals (Banerjee and Dash, 2011). Selling strategies employed by pharmaceutical companies rely on a mix of personal and communication skills (Ahearne et al., 2007; Alkhateeb et al., 2009) along with reliance on scientific information obtained from the literature (Alkhateeb et al., 2009). Despite efforts to build relationships with physicians, the detailing model in use is centred primarily on the need to 
shape and communicate value to health care professionals, as opposed to the engagement of the client in the value creation process (Chimonas et al., 2007).

Recent evidence sheds light on the saturation of detailing as a selling model (Hilsenrath, 2011; Morgan, 2010). A key explanation is that health care professionals such as physicians are not motivated to engage in relations with pharmaceutical representatives, since they may not see such interactions as value added anymore (Hilsenrath, 2011; Morgan, 2010). Hence, companies within the pharmaceutical industry need to evolve their model rapidly if they want to remain profitable, and hence continue to look for innovative approaches to market their products that will provide them with a long-lasting competitive advantage.

\section{Towards value co-creation through SAM}

Although a plethora of books and journals exist on the topic of SAM, very few of the ideas and concepts generated in the literature address medical markets specifically; the peer-reviewed academic literature on the SAM business model within pharmaceutical companies is scarce.

Smith (2009) looked into the applicability of SAM in pharmaceutical markets and proposed a number of critical elements to consider when adopting a SAM model in pharmaceutical companies: (1) SAM depends on effective targeting: beyond the typical volume criteria, key accounts must also be able to deliver non-financial-value and, critically, be willing and able to enter into a relationship. "In many therapy areas, the clinician/purchaser power balance is still such that the organisation (i.e. hospital/account) is unable to act as an entirety" (Smith, 2009, p. 92), or even when it is possible, the internal culture of the customer organization hinders them from entering into long-term, mutually trusting relationships because their history and habits predispose them towards transactional, almost confrontational, relationships with suppliers. (2) 
SAM requires rare knowledge assets: Strategic account management usually depends on the supplier having superior knowledge of and superior relationships with the customer at all levels of the organisation (Smith, 2009). (3) SAM requires organisational change: The traditional hierarchical structure observed in pharmaceutical sales organograms, designed to maximize efficiency and control, where short-term results are a priority and where political game playing is frequent, is rarely appropriate for SAM: nowhere is the old adage "structure follows strategy" (Chandler, 1990) more true than with the SAM model. Successful SAM functioning requires innovative reporting structures that are often account-specific (Smith, 2009). (4) SAM requires different approaches to measurement: The multidimensional nature of "value creation" in SAM is fundamentally different to the goals in a traditional sales model, and this implies that similarly sophisticated Key Performance Indicators (KPI's) must be put in place. Lag indicators of sales, profit and market share need to be replaced with a broader range of qualitative and quantitative KPI's that both lead and lag outcomes. Again, such a shift in thinking is a cultural paradigm shift for most pharmaceutical companies (Smith, 2009). (5) SAM requires organizational learning: SAM requires a company to constantly test what is being done against its value generation and relevance. If a pharmaceutical company thrives on a product-led culture, the implementation will be more arduous, whereas open, learning organizations will be more successful (Smith, 2009).

Another interesting paper on SAM in the pharmaceutical industry by Vanderveer (2002) discusses the dynamics of this business model and its all-around value. Vanderveer's (2002) recommendations have merit in that they do bring up the concept of value creation, but overall lack specificity and cohesion in terms of theoretical modelling. His research presents a credible argument to support account management as the way of the future for pharmaceutical companies, but does not offer a recommendation on how to actually implement such a model. 
While strategic account management is an under-researched area in relation to the pharmaceutical industry, very few studies have explored SAM in this industry in relation to value-creation; i.e. the way relations with clients allow companies to create products and propositions that convey value to the client (Storbacka, 2012; Vanderveer, 2002; Vargo and Lusch, 2008). Value creation could help explain the conditions under which pharmaceutical companies could offer better added value in their interactions with their key clients.

The pharmaceutical industry needs to depart from the traditional selling model (e.g. detailing), which centres primarily on generic value propositions. Value co-creation could be a means through which this industry can improve the added value of their offerings to achieve better customer satisfaction and loyalty. The present study focuses on SAM as a means through which value co-creation can be established (Storbacka, 2012; Vargo, et al., 2008).

The present study is set to investigate the dynamics that are essential for SAM to function as a value co-creation selling model in the pharmaceutical industry. This research is carried out within the branded pharmaceutical industry in Canada. This is a context which can help offer fresh insight into our understanding of SAM as a value co-creation model in the hospitalpharmaceutical company interexchange.

\section{Methodology}

For pharmaceutical companies, institutional customers like hospitals are ideal partners with whom to implement a SAM model. Indeed, the literature states that one of the market environment conditions historically associated with a shift to a SAM approach is the increased sophistication of the buyer (Gosselin and Heene, 2005); given that institutional customers like hospitals are seeing an emergence of increasingly complex stakeholder networks and decision- 
making processes (Wartenberg and Gores, 2008), there is solid theoretical ground for pharmaceutical companies to focus on hospitals as strategic accounts.

To that end, and given the efforts to research the dynamics for SAM to become a value cocreation model, data was collected within hospitals as (potential) strategic accounts of pharmaceutical companies. Given the focus on the customer, the study sheds light on the customer (i.e. hospital) perspective of SAM as a value co-creation system (as opposed to a more holistic understanding that would bring together the views of both parties in the relationship). In pursuing insight on this relatively unexplored phenomenon, a case study research method was adopted (Eisenhardt, 1989; Eisenhardt and Graebner, 2007; Yin, 2013). Particularly, a multiple case study research was employed (Eisenhardt, 1989; Yin, 2013), each case representing a different hospital. The organization was considered as a unit of analysis due to the focus on the hospital needs and expectations in its business relations with pharmaceutical companies. Multiple case study research allowed conducting cross-case pattern search, investigating the evidence through multiple lenses, and obtaining a saturated understanding of the phenomenon at hand (Eisenhardt, 1989; Eisenhardt and Graebner, 2007). These processes enabled identifying patterns, themes, and relationships replicated across cases (Eisenhardt, 1989; Yin, 2013), helping to build theoretical understanding that would generalize across the participating cases (Eisenhardt, 1989).

To identify relevant cases, purposive sampling (Bryman and Bell, 2015; Morse, 2004) was used; i.e. hospitals were chosen (purposefully) so that these would reflect a diverse blend of varying types of hospitals in Canada, ranging from small to large, academic to community-based. This was done in order to drive a true representation of the Canadian healthcare environment. This would ensure a saturated understanding of the phenomenon under investigation and secure 
efforts to build a theoretical framework that would generalize across the participating organizations (Eisenhardt, 1989; Eisenhardt and Graebner, 2007; Yin, 2013).

The reasoning that was used to carry out and make meaning out of multiple case study was mainly inductive (Bryman and Bell, 2015; Yin, 2013). Despite carrying out a loose assumption on SAM as a value co-creation model, the authors of the present study have investigated the phenomenon in an open manner allowing the research participants to elaborate fully on their own understanding on how a client-supplier (in this case a hospital-pharmaceutical company) relationship could become fruitful and value added. Given the 'customer perspective' of the study and the consideration of hospitals as strategic accounts of pharmaceutical companies, the research participants were asked to recall relationships of their hospital with any pharmaceutical company (not one specific relationship). Thus, the research participants have addressed several different suppliers (i.e. pharmaceutical companies) during the interviews.

In-depth interviews was the key instrument employed to gather relevant data from each case (Yin, 2013). To obtain the information needed to build a theoretical framework relevant to the dynamics underpinning SAM as a value co-creation model (in the pharmaceutical industry), interviews were conducted with hospital directors. To ensure a strong cross-representation of the important decision makers within a hospital setting, numerous levels of senior management were approached (in this case: CEO, VP, Pharmacy Director, and Medical Director). While initially a single interview took place with a key decision maker in each hospital, subsequent visits to the research sites led to the collection of data from an additional decision-maker. This was done to ensure a more rounded understanding of the phenomenon within each participating organization, in line with the case study methodology (Yin, 2013). In total, twenty-two hospital directors were interviewed, representing eleven hospitals. Table 2 outlines basic characteristics of each of the 
participants and their respective organizations (i.e. hospitals). Interest in participating in the qualitative research was solicited partly through the Canadian College of Health Leaders.

\section{Insert Table 2}

The interviews were approached from a flexible, facilitative and open-ended position, to allow sufficient elaboration on the topic in line with the need to gather relevant emergent understanding for theorization purposes (Eisenhardt and Graebner, 2007). Since a customer perspective was pursued, the aim was to design a customer-centric interview guide. Thus, the overarching phenomenon and interview topics were introduced in a language that would enable the research participants to comprehend fully the areas of discussion. For example, interviewees were not asked to discuss directly topics such as SAM or value co-creation. Instead they were asked to discuss the relationships of their organizations with pharmaceutical companies, areas of hospital-pharmaceutical company relations being critical to hospital functioning, understandings for improved hospital benefits from such relations, suggestions on how to make such relations enduring, etc. A pilot study was conducted within one hospital (two interviews) to test the initial interview guide. Following the pilot, additional refinements led to the design of a research instrument that was closer to the language and understanding of the research participant and would allow eliciting all necessary information on the study's phenomenon.

No prior theoretical lens was imposed and efforts were centered on emergent insight and emergent relationships, which would set the grounds for a new theory on the phenomenon at hand (Eisenhardt, 1989; Eisenhardt and Graebner, 2007; Yin, 2013). In analysing the data, an inductive coding process was employed to allow linking and incrementally proceeding from data 
to theory (Corbin \& Strauss, 2008). Initially, open coding was used as a means of identifying, relevant to the topic, concepts and themes. Subsequent rounds of axial coding allowed in understanding relationships between initial codes and themes and larger categories underpinning the meaning of the data (Corbin and Strauss, 2008; Miles and Huberman, 1994). All the study's key themes emerged inductively as part of the inductive coding process that was employed, without any prior consideration of existing literature. Key themes and sub-themes (e.g. 'customer-tailored value added initiatives', 'tangible benefits to hospitals', 'value linked to QIP Goals' etc) were first identified, then linked between them, and then the authors moved on to review existing literature to get a sense of new and existing concepts reflected in the findings (Gioia et al., 2013). It was after linked to literature (Gioia et al., 2013) that the authors of this article understood how their research would contribute to the fields of 'strategic account management' and 'pharmaceutical marketing'.

Through interpretative analysis (Moisander and Valtonen, 2011), the interview responses were used to derive an understanding on how relationships in the hospital-pharmaceutical company interexchange can become more meaningful and value added. Participants' meanings had a central role in the analysis and presentation of findings, as well as on the conceptualisation of emergent concepts and relationships.

\section{Results}

Two concepts have emerged from this research, which appeared to shed light on the dynamics allowing SAM to become and function as a value co-creation selling model in the pharmaceutical industry. First, the 'customer-tailored value-added initiatives' will be explored in 
detail, followed by a review of the 'relationship enhancers' in the hospital-pharmaceutical company interexchange, as reported by the customers themselves.

\subsection{Customer-tailored value-added initiatives in the hospital-pharmaceutical relationship}

As emerged from the findings, 'customer-tailored value-added initiatives' are important in making SAM a value co-creation selling model in the pharmaceutical industry. These initiatives refer to actions on behalf of a supplier (in this case the pharmaceutical company) that focus on the specific needs of a client (i.e. the hospital) and lead to the creation of unique value for this client. As articulated by the research participants, hospitals are in need of relationships with suppliers (i.e. pharmaceutical companies), which embed initiatives that can help generate value that suits their individualistic needs and idiosyncratic contexts.

More particularly, the findings suggest two dimensions of value-added initiatives, which can allow the customer-tailoring of value to take place. These include: a) Initiatives that generate value linked to Annual Quality Improvement Plans, and b) Tangible benefits that are very specific to the realities and context of each hospital. These dimensions are explained in more detail in the sections that follow.

\subsubsection{Customer value linked with Quality Improvement Plan (QIP) goals}

Key organizational goals of hospitals in Canada are reflected in their respective Quality Improvement Plans. The Excellent Care for All Act (ECFAA) requires that hospitals develop an annual Quality Improvement Plan (QIP) for the following fiscal year and make that plan available to the public. The QIPs are an opportunity to highlight a hospital's goals, which mainly revolve around the following needs: delivering high quality health care, creating a positive 
patient experience, ensuring that it is responsive and accountable to the public, holding its executive team accountable for its achievement, and being transparent (Ontario Ministry of Health, 2012).

The research participants explained the central role that QIPs hold in the relationship between a hospital and a pharmaceutical provider. As explained, since QIPs are an adequate reflection of hospital individualistic conditions, providers that are aware of a hospital's QIP can adjust their support accordingly. Participants agreed that QIPs should be the basis for discussions with pharmaceutical companies about any given hospital's Key Performance Indicator's and areas of focus. Frank, VP of patient services at a large community and teaching hospital (\#5), said: “It's simple: just like a physician needs to know everything there is to know about a patient's condition and health goals by looking into the patient's chart, a pharmaceutical provider should know about a hospital in a similar way by looking at the QIP: the QIP gives insights into the current status on the hospital in term of problem areas and direction it wants to go in”. Mary (hospital \#3) added: “it is imperative for key suppliers such as pharmaceutical companies to be aware of our Quality Improvement Plan so that they understand our priorities".

It was implied by some participants that it is an advantage for any pharmaceutical company to know as much as possible about a hospital's quality improvement metrics when dealing with its decision makers, but it was also mentioned that this is rarely observed in real life. Bob (hospital \#1) commented: "I don't typically expect a vendor to know about my goals, but when they do, they automatically have insight into what is of importance to me. I don't meet many representatives who actually take the time to investigate". As it was explained understanding this dynamic more thoroughly is essential in the hospital-pharmaceutical supplier interexchange. To this end, the participants mentioned three key goal categories of a hospital QIP, which they said 
that pharmaceutical companies should be aware of for relevant support provision. These are goals relevant to safety, effectiveness, and access. While these goal categories appeared to relate to all participating hospitals, the findings stressed the need to look into the content of each hospital's goal to get a grasp on how a hospital would be best served.

First, as it was explained, having safety goals is an enormous priority for a hospital. Patrick, a VP of Patient services at a large teaching and research center (\#3) associated with the largest University in the province, stated that a safety agenda was their top priority: "A safety agenda is a proactive approach to avoiding risks. Our goal is to avoid and prevent any negative event on a patient's health that could stem directly from being in the hospital environment. Also, having a safety agenda includes ways to effectively and rapidly address issues when you have them". The findings illustrate the role that pharmaceutical companies can play in improving the safety of care in a hospital by helping, for example, to control hospital-acquired infection rates. Bob (hospital \#1) provided the following thoughts: “A pharmaceutical company can assist with the provision of the needed education and knowledge so that hospitals use antibiotics appropriately”. Paul (hospital \#2), added: “Patient safety is paramount and pharmaceutical companies have the capacity and infrastructure to support us in this endeavor".

Second, having an effectiveness goal was mentioned by participants as being equally important. For example, senior management and pharmacy directors are responsible for balancing the budget, and in doing so, must consider the impact of their choices (e.g. pharmaceutical products) not only to the immediate budget they are responsible to manage, but also to the hospital's Total Margin ${ }^{1}$. Brian (hospital \#7) best describes his responsibility in ensuring the hospital he works at is as effective as possible: "Being able to provide quality care

\footnotetext{
${ }^{1}$ Total Margin is defined as follows: percent by which total corporate (consolidated) revenues exceed or fall short of total corporate (consolidated) expenses, excluding the impact of facility amortization, in a given year.
} 
at a price point that is actually going to meet the funding formulas for the province [...] is my challenge. We cannot skimp on medications which cause the patient to stay for an extra three days, or go with a product just because it's cheap but causes all kinds of side effects and complications: we are responsible for the broader view of effectiveness". Scott (hospital \#6) provides a thoughtful perspective about the pharmaceutical firm role in improving hospital effectiveness: "To be able to deliver effective service, we must focus on developing our clinical and distribution expertise, our educational skills, and we cannot do so without the needed support by pharmaceutical companies"

Third, the research suggests that hospitals, every year, have a focus on improving access; with relevant actions set in line with each hospital's needs and circumstances. An example of an access-specific goal that was mentioned was a hospital's need to improve wait times for patients whether it is at the Emergency Room (ER) level, or surgery/Operating Room (OR) level. "Wait times have improved over the past decade, with better triage and more stringent protocols which provide clearer guidance to physicians, but we are far from being where we want to be. We can always improve how we do things, especially with the aging population which should increase flow through the ER over the coming decade”, says Gareth, VP of patient services at a mid-size community hospital (\#9). The research participants stressed the role of pharmaceutical companies in helping the hospital improve access. Bob (Hospital \#1) mentioned: "Pharmaceutical companies with their inventions can help support hospitals in treating patients faster and more effectively than before and as a result becoming more accessible and able to reduce patient wait times".

The findings suggest that value co-creation is deeply embedded in the interaction between pharmaceutical company and hospital, where the first can improve customer value if tailoring its 
offerings and overall support to each hospital's QIP metrics. Such an approach may imply, at the same time, higher engagement from the customer to make sure that the provider becomes aware of a hospital's unique QIP priorities. Further, SAM can emerge as a value co-creation model when a pharmaceutical supplier is oriented towards supporting a hospital in improving quality through fulfilling specific safety, service effectiveness, and access goals.

\subsubsection{Tangible benefits specific to hospital context}

The participants acknowledged having used help from sources external to the hospital to help them achieve their goals. However, the perceived value of external support varied greatly among participants, which may be due to differences in the context of the hospital, and will be analyzed in detail. Participants mentioned that the only time any kind of support is perceived as valuable is when there is a significant time or financial commitment on the pharmaceutical provider's part to a significant hospital issue. The major categories or types of value-added external support that hospitals mentioned receiving are: subject-matter expertise, risk-sharing agreements, awareness/ education campaigns, in-kind support and financial support. However, it was articulated that support under each of these categories can be as diverse as the specific circumstances of each hospital client.

First, participants mentioned that a number of issues and/or opportunities may arise in a hospital setting which existing staff has neither the knowledge nor skill-set to leverage, and hence subject-matter expertise from outside the hospital may be required. An example of this was mentioned by James, CEO of a small hospital (\#4), where their hospital used the services of a pharmaceutical company to allow completion of a complex special project: "Last year, we enjoyed the support from a pharmaceutical company and a couple of external physicians in 
order to develop a treatment protocol for dealing with patients admitted with a Myocardial Infarction. Without this external support, we could not have managed it”. Patrick of hospital \#3 mentioned an interesting use of a pharmaceutical supplier's capabilities to benefit their own hospital: "A few years ago, in an attempt to improve our quality improvement culture, our hospital used, free of charge, the services of one of our pharmaceutical suppliers. This company significantly helped us address our issues, and in doing so, further solidified their relationship with us". George (hospital \#6) echoed: "A pharmaceutical company shared some of their practices to help us in our endeavors to re-engineer our HR division. A small hospital like ours can certainly benefit from the expertise of a large organization".

A second type of support that participants mentioned having established with external suppliers is risk-sharing agreements. The research suggests that in some instances, hospitals have benefited from a vendor wanting to share some of the risks associated with the purchase of a product or service with the purchasing hospital. Bob, pharmacy director with hospital \#1 explained: "The hospital will agree to buy a product or service at market price from a company under the condition that the so-called product or service delivers on its promise, for example, to save other costs, to reduce wait times, or to get people back on their feet faster". Nik (hospital \#5) was more explicit: "Risk sharing is a must in a contract with a pharmaceutics supplier, especially in the case of new medicines or equipment that haven't largely used".

The research shows that a third type of support to hospitals comes in the form of awareness and education campaigns. There are a number of companies, as mentioned by participants, who help develop and implement awareness or education campaigns. An example comes from a pharmaceutical company that developed a campaign entitled "Just wash your hands" (Peter hospital \#1) to encourage patients entering the hospital to make use of the antiseptic soap readily 
available. Bob (hospital \#1) elaborated: "This initiative was perfectly aligned with the goal of reducing infection rates at our hospital, while also being an area in which the supplier had tremendous expertise, given that the partner was a pharmaceutical company that developed and marketed antibiotics for decades”. Andrew (hospital \#7) said: “We certainly obtain value as a hospital from campaigns of pharmaceutical companies that offer information - for example on HIV or cancer. More informed patients are more collaborative”. Such types of supporting educational initiatives were clearly flagged by interviewed participants as true value-added services that helped their hospital improve patient care. Participants mentioned that the consequence was increased trust by hospital management in these particular companies.

In-kind support was mentioned by participants as another type of support that was, at times, provided by external suppliers. A few participants mentioned having received non-monetary support from their pharmaceutical suppliers in the form of "borrowed" infrastructure (e.g. meeting rooms) or administrative services. For example, James (hospital \#4) said the following: “We recently used a vendor's state-of-the-art meeting facility that is about 60 minutes away from our hospital for one of own hospital management team off-site meetings”. Lucas (hospital \#11) added: "They (talking about a pharmaceutical supplier) maintain infrastructure which they always allow us to use when we undertake staff trainings. We want to see more of this from other suppliers as well". However, it was agreed that in-kind support such as this could not compare favorably to the value-add of an initiative that directly furthered patient outcome and enabled a hospital to meet some of their specific goals.

Financial support to purchase new equipment, new technology, or simply to fund the expertise hired (and described above) was also mentioned as a valuable. Frank (\#5) mentioned: 
"Obviously, any time I get money to cover the cost of a specific initiative I have going, it helps me. Some companies are good with providing blank checks”.

The findings illustrate that the value for a key pharmaceutical client such as a hospital is deeply rooted and developed in a customer-supplier relationship which allows the first to obtain benefits that are fully aligned to their own practice, goals, and needs. The section that follows focuses on the hospital-pharmaceutical company relationship, explaining the relational dynamics that are essential in allowing SAM to emerge and function as a value co-creation selling model in the pharmaceutical industry.

\subsection{Relationship enhancers: Critical elements in a hospital-pharmaceutical company relationship}

This section sheds light on a second concept, which appears to shed light on the dynamics allowing SAM to become and function as a value co-creation selling model in the pharmaceutical industry. This is the "relationship enhancers", which refer to forces that can help strengthen hospital - pharmaceutical company relations and allow the first to enjoy value that is directed to their individual needs and demands. A number of "relationship enhancers" emerged from the research: a) being centred on customer-need; b) striving for long-term partnerships; c) representing the entire company portfolio; d) measuring and sharing the impact of initiatives; and e) building relationships at all levels of the organization.

Further, the findings suggest that these "relationship enhancers" relate heavily with the "customer-tailored value-added initiatives" explained in the previous section; this relationship appears to be cyclical: 'Relationship enhancers' underpin and strengthen value added initiatives that are tailored to the needs of the customer (i.e. the more the relationship is enhanced, the more 
the client perceives unique added value from pharmaceutical company initiatives); Relationship enhancers' influence is magnified when pharmaceutical company initiatives are perceived as value added (i.e. the more a pharmaceutical company pursues initiatives that are conceived as value added by the customer, the more the 'relationship enhancers' can allow strengthening of the client-supplier relationship).

First, participants described the importance of a hospital-pharmaceutical company relationship that is centered on the needs of the customer as a critical factor in driving customerperceived value, and hence in developing a solid hospital-pharmaceutical company relationship. As it was explained earlier, the findings illustrate that hospitals as key customers (of pharmaceutical companies) perceive an offering as valuable when it clearly meets their goals and context. Helen (hospital \#10) said: “A b2b relationship to be successful needs to center on the needs of the customer. This is what should prevail also in our interactions with pharmaceutical suppliers". The findings suggest that the ability to adjust offerings and support on the individualistic needs and context of the client stems from an ability to establish a relationship with the client that values customer individuality and contextual boundedness. At the same time, the findings illustrate that by being centered on the needs of a hospital, a pharmaceutical company is more able to build a stronger relationship with the hospital (as a key client), which can be fruitful and mutually beneficial over the long term. To this end, Bob mentioned: “A large check to support an initiative that has little value for my needs, and hence the patient, is in the end money wasted. Instead, I prefer the company drops its product price point in order to enable me to roll-out a truly value-added program with the money I saved. This can happen if a pharmaceutical provider understands our exact needs and this is a passport for establishing a truly long term mutually beneficial relationship". Martin echoed: "Value added is when we 
achieve a goal that is of high priority and flagged within our publically accessible QIP. Thus, any relationship that we build with a supplier of pharmaceutical products which can allow us achieving such goals, is definitely of the utmost value to us. Of course, it also helps strengthen our interactions further...".

A second critical theme that emerged was how striving for long-term partnerships on the part of a pharmaceutical provider was integral in driving a deeper and more trustful customersupplier relationship. The findings also suggest that long term partnerships are critical in driving initiatives that are value-added to the specific client but also in strengthening the customersupplier relationship as a result of ongoing customer value creation. Alan (hospital \#9) said: "Such a relationship should be established on long-term grounds". Bob (\#1) elaborated more on this issue, stating that partnerships are built over time and require a long-term approach in order to be successful. "Some pharmaceutical companies come to me and say: 'We want to partner with you. What could we do in the next few weeks?' That, to me, demonstrates that the supplier does not understand the world I live in, and the challenges I face. To succeed, relationships should become long term partnerships that will allow pharmaceutical companies to generate offerings and services that reflect our world. This is how a relationship can become valuable and this is how relationships can be sustained". Another participant, Gary (\#11), supported this thought: "Providing me with your services or money for you to benefit immediately with no consideration for my long-term goals is not going to get you very far". John (\#10) added the following: "Pharmaceutical companies should try to predict what the problems are going to be, two or three years out, in collaboration with the hospitals, instead of looking primarily at the next quarter's revenue or profit". 
Third, participants expressed frustration from having to deal with multiple individuals from the same company. They stated a preference for dealing with individuals who represent the entire portfolio of their company (and not just a department, or Business Unit). Often, hospital senior managers mentioned they find it of value to establish a partnership with a vendor when one person can answer ALL their questions, and source the optimal solution from all product or service offerings from this company. Frank (\#5) mentioned: "The increased perceived-value stems from the belief that an agreement is more robust and beneficial if it covers a wider array of products and services - which often times will be the case for both parties". One example provided by Martin (\#2) was how a representative from a pharmaceutical company managed to leverage discounted products from other Business Units within his company - an ultra-sound machine- to "sweeten" the deal on the purchase of specialty drugs. He mentioned: "This was a 'one-off' offer that was never repeated but it brought a lot of value to our hospital, and this initiative went a long way for the representative who made this happen for us".

Fourth, participants mentioned one additional factor that improves the relationship, and even at times may serve to establish the initial grounds on which to develop a relationship: participants expressed the need for the supplier to measure the impact of the value-added initiatives developed, and when possible, to share the results freely within the account and across with other hospitals. "The only way to change the opinion of the pharmaceutical industry detractors, i.e. the people who have a negative opinion of the industry, is to demonstrate to them that your initiatives have actually bettered patient outcome" very cleverly states Bob (\#1). Gareth (\#9) reinforced this thought with the following comment: "If the initiatives you helped develop were actually successful, then by all means, you should be telling the whole world, and 
especially the customers who are skeptical and do not believe any good can come from a hospital-vendor partnership."

A final critical driver to the hospital-pharmaceutical company relationship was the importance for the latter to build relationships at all levels of the organization. In other words, it is important for the pharmaceutical provider to understand the individual responsibilities of all departments within the hospital in the decision-making processes and to tailor their approach to them. Although senior management participants in the research (CEO's and VP's) mentioned that they are accountable for delivering against all goals, they also stated that the day-to-day operations and the "how-to" are delegated to departments. One CEO (\#4), James, mentioned: "Of course, I want to know about any initiative that could impact our ability to reach our goals. However, I am not interested in the details, at least not until the initiative is fully hashed out. You are wasting time if you try to get me involved in the details”. Another CEO (\#2), Martin, added: "Similar to any business, I delegate responsibility, and partial accountability, of addressing certain goals in our QIP to departmental heads. They are the ones driving all the activities. They may consult with me at times, but they drive the boat". Conversely, participants also mentioned that for the partnership with the hospital to be long lasting and solid, a company needs to ensure senior management is involved every step of the way, or at the very least, kept in the loop. "You need to think holistically, because at the end of the day, it only takes one important decision maker that is not on board or knowledgeable about your endeavors with our hospital to get in the way of your objectives", mentioned Frank (\#5). Rico (\#8) added: "I see myself as an insurance policy for the SAM or the company that delivers value. It may be the pharmacy director and departmental heads that drive formulary inclusion decisions for products in any given therapeutic area, but I can intervene if I believe it is best for the hospital and the patients". 
The findings illustrate the need to consider a number of key elements that can contribute towards the enhancement of hospital-pharmaceutical company relations. It appears that a hospital-pharmaceutical company relationship can only address QIP considerations and tangible benefits to a hospital (i.e. value added that is tailored to the needs of the hospital) through the establishment of a close and long-lasting relationship between the two parties. At the same time, the hospital-pharmaceutical company relationship can be further enhanced through initiatives that are conceived as value added by the customer. The section that follows offers a conceptual model that depicts the study's emergent concepts and the relationships between them. It also discusses the findings in relation to existing literature.

\section{Discussion}

The present study sheds light on the dynamics leading to value co-creation in the hospitalpharmaceutical company relationship, explaining how SAM can emerge and function as a value co-creation selling model in the pharmaceutical industry. The conceptual framework in figure 1 reflects the study's findings and provides answers to its research question.

\subsection{SAM as a value co-creation model}

Our findings offer fresh insight in the field of strategic account management, through a perspective of SAM model that relies on ongoing value co-creation between a customer and a supplier. Our research sheds light on Strategic Account Management as a client-centred selling model, which can lead to co-creation of value with the client, helping an organisation to delve beyond value creation embedded in predefined output (Gosselin and Heene, 2003; Gosselin and Bauwen, 2006; Vargo et al., 2008). This conceptualisation of strategic account management, can help understand SAM as a system that shapes high-quality interactions between the organisation 
and individual clients with the view to co-create products, services, and/or experiences that take into account the client's peculiar circumstances (Prahalad and Ramaswamy, 2004). This way, long term productive relationships with strategically important customers can be established through efforts directed towards higher client engagement and co-ownership of the process leading to value creation that is tailored to the needs of the client (Berghman et al., 2006; Cannon and Perreault, 1999; Gosselin and Bauwen, 2006; McDonald et al., 1996; Storbacka, 2012).

Figure 1 illustrates the key value added and relationship-specific dimensions, which relate in a cyclical manner to explain the dynamics that are essential for SAM to to function as a value cocreation selling model in the pharmaceutical industry model. These dimensions are discussed in detail below.

\section{Insert Figure 1}

\subsection{Value-added tailored to hospital needs}

The present research demonstrated that customers value initiatives that are tailored to their specific needs and contexts. One critical dimension, which can allow customer tailored value added involve pharmaceutical company-driven initiatives that can support a hospital in achieving its organizational goals. To that end, the Quality Improvement Plan (QIP), which all hospitals are obligated to develop and make publicly accessible through their websites, can be used as a good identifier of the important goals of any given hospital. Consequently, the QIP content is important and arguably a good starting point for any pharmaceutical company trying to uncover how to bring unique value to a key client such as a hospital. The research findings suggest that the key quality metrics that should be targeted by a pharmaceutical company to establish a foundation of value-creating opportunities are safety, effectiveness and access. Moreover, once a value-creating opportunity has been identified, the research suggests that considerable thought on 
the part of the SAM needs to be put into how a value-creating initiative is developed and implemented. The research suggests a number of types of initiatives to consider implementing when trying to bring unique value to the hospital: subject-matter expertise, risk-sharing agreements, awareness/education campaigns, in-kind support and financial support. The findings illustrate that these pharmaceutical company-driven initiatives to be perceived as value added by a hospital need to become specific to the needs and contexts of the latter. These findings reflect a customer-supplier relational model that is driven by the need to adapt value to the context of the client so that a customer's experience is maximized (Cannon and Perreault, 1999; Gosselin and Bauwen, 2006; Prahalad and Ramaswamy, 2004; Vargo and Lusch, 2008). This is an approach that reflects the realities of a value co-creation system where client individuality and idiosyncrasy are highly considered (Homburg et al., 2002; Piercy, 2009; Storbacka, 2012). The findings suggest that if a SAM system is driven by the need to individualize value creation, then customers are more likely to perceive supplier initiatives as beneficial.

\subsection{Relationship enhancers within SAM}

The literature reports that SAM fulfills the role of an enabler or promoter of an existing relationship (Bacon, 1999), with the task to manage the relationship and optimize the fit between the supplier's value offer and customer's needs (Weitz and Bradford, 1999). The present study contributes to the literature on SAM by offering a context-specific understanding of the relationship enhancers within SAM. The findings reflect the idiosyncrasies of the pharmaceutical market where key accounts of pharmaceutical companies are hospitals (Wartenberg and Gores, 2008) and efforts should be directed in strengthening relationships with these organizations. Five 
drivers surfaced from the research as important to managing hospital-specific relationships: focusing on customer (i.e. hospital) needs, striving for long-term results and partnerships, representing the entire company portfolio, measuring and sharing the results, and building relationships at all levels of the organization. The present work builds on previous studies on SAM that illustrate the importance in focusing on the individual needs of each key customer (Gosselin and Bauwen, 2006; Storbacka, 2012; Vargo and Lusch, 2008), in establishing longterm partnerships with them (Vanderveer, 2001), and in matching seller and buyer relationship requirements (Piercy and Lane, 2006).

The present study helps also in unveiling new dimensions in SAM implementation and functioning, which are not reflected in previous work. First, the findings demonstrate that a supplier who wants to develop a partnership with a hospital must access the company's entire portfolio of products and services in order to build a relationship with the most chances of longterm continuation. Hospitals seek unique and innovative solutions that require out-of-the-box thinking, and the supplier can more easily provide the answers if it can pull from a more vast pool of resources. Second, the findings suggest for the supplier to conduct an analysis, where the impact of the initiative developed in collaboration with the hospital is assessed in terms of customer-perceived value, and weighted against all the resources utilized to elaborate the initiative. Also, in cases where satisfactory results are observed, the research suggests that they need to be shared with other customers in order to convince them of the potential value created by developing partnerships with this particular supplier. To that end, the present study unveils the potential benefits of having the results shared not only with society in general, but more specifically with skeptical hospital customers that do not believe in the value that partnerships with their suppliers could bring. A third driver not reflected in previous work suggests a 
relational foundation on which to establish all interactions. Indeed, participants suggest that they cannot all contribute value to the supplier in similar ways. This research suggests that different objectives and expected outcomes exist when developing relationships with varying levels of management within a hospital.

The section that follows offers a summary of key findings and discusses the study's key contributions, implications, and limitations.

\section{Conclusions}

The present study sheds light on a number of dynamics that can explain the emergence and functioning of SAM as a value co-creation system in the hospital-pharmaceutical relationship (which is the dyadic relationship on which the authors of this article have focused to address their research question). These dynamics are understood in the presence of two key dimensions: 'customer-tailored value-added initiatives' and 'relationship enhancers'. Customer-tailored value-added initiatives explain the type of activities that are central to the hospitalpharmaceutical company relationship and can enable the provision of value added that is unique to the needs and context of the hospital. These initiatives involve activities that a) help hospitals establish and communicate their annual quality improvement plan, and b) offer tangible benefits that are specific to the realities and context of each hospital. The findings suggest that these initiatives are driven by the relationship and allow the creation of unique value through the active involvement of the customer (i.e. the hospital). Relationship enhancers explain the activities that can help establish a hospital-pharmaceutical company relation that is underpinned by value cocreation and the generation of value added that is unique to the client (i.e. the hospital). 
This research demonstrates a cyclical relationship between 'customer-tailored value-added drivers' and 'relationship enhancers': relationship enhancers enable the provision of products and services that are tailored to the needs and context of the individual customer (i.e. the hospital); when the hospital perceive enhanced value added from pharmaceutical company initiatives, 'relationship enhancers' influence is magnified to allow more sufficient and ongoing understanding of the customer context.

\section{Theoretical and Empirical Contributions}

A key theoretical contribution of this work is the conceptualisation of 'SAM as a value cocreation system'. This concept has emerged drawing upon an inductive reasoning, and explains the dynamics that should underpin customer and supplier (in this case a hospital and a pharmaceutical company) interactions to allow value to be created that is bounded in the context of the individual client. This theoretical framework brings together a number of researchemergent concepts to shed light on relevant dynamics and a cyclical relationship that can allow SAM to emerge and function as a value co-creation selling model.

The present study offers empirical contributions to the fields of strategic account management and pharmaceutical marketing. It contributes to the field of strategic account management through insight on SAM as value co-creating approach. Previous studies illustrate the importance of SAM as a value creation system (Gosselin and Bauwen, 2006). The present article extents this understanding by shedding light on the way SAM can allow a customer-supplier relationship to become more value added to the client through a system of value co-creation.

Further, the present work contributes to the field of pharmaceutical marketing by offering empirical insight on the conditions leading to a selling model that is perhaps more value-added 
from the traditional systems in use. It introduces knowledge in an area that currently lacks sufficient understanding on the applicability and use of SAM in the hospital-pharmaceutical company dyad. The present study suggests a new approach to be considered in the context of pharmaceutical marketing endeavors. Moreover, it sheds light on how value co-creation and the way this can be seen to unfold in the pharmaceutical industry. This can be seen again as a key contribution to the field of pharmaceutical marketing, which is primarily centered on product driven perspectives (Wenzel et al., 2014), and could shift into approaches that can allow better appreciation of the needs and contexts of key clients.

\section{Implications for practice and policy}

The present study has implications for industry practitioner (pharmaceutical industry executives and sales people). Indeed, findings demonstrate that a number of conditions play in to how value-added opportunities for customers should be identified, developed and implemented. For example, the Quality Improvement Plan represents a significant source of potential initiatives on which to elaborate a SAM strategy. Additionally, the framework proposes a holistic approach to relationship management, which contributes to the practitioner's SAM implementation plans. The proposed framework could, in fact, serve as a challenge for pharmaceutical practitioners to experiment with a new model that can enable them to shift away from existing selling practices which seem to be inflexible and non-sustainable. Experimentation and further adaptation of the dynamics referred to in the proposed model may allow pharmaceutical companies to radically change their marketing and selling perspectives and, perhaps, become more client centered and informed as to how to contextualize their offerings to each client's reality. Value co-creation via a SAM model could be the means through which 
pharmaceutical companies can delve into a more client centric selling model and thus an innovation that can lead to improved pharmaceutical marketing.

There are also implications for policy makers. Canadians not only pay high prices for drugs, but heavily subsidize the development of new products (Petit, 2012). This issue has partly contributed to the hostile environment in which pharmaceutical companies find themselves from a public opinion perspective (Sillup and Porth, 2008). The study explores the QIP-centric (and thus indirectly patient-centric) value-creation process that is possible through the implementation of a SAM model, and thus provides government authorities arguments on the value, from a societal perspective, of investing in pharmaceutical companies when wanting to justify public investment in this industry's R\&D. Moreover, the association of leading research-based pharmaceutical companies in Canada, can consider using the SAM model's value-creating potential to also heighten its reputation among Canadians. The results of this study suggest that a shift in the selling business model from the old "frequency" approach to a SAM approach could improve the perception that both the medical community and the public have of pharmaceutical companies. Policy makers at the governmental and national industry association level could benefit from investigating this upside further.

\section{Future research}

The present work sheds light on dynamics allowing SAM to become a value co-creation system in the context of the customer-supplier relationship. More explorative research is encouraged to shed further light on the links between SAM and value co-creation. This way the literature can become more informed on the value co-creation qualities of strategic account management. Further, the theoretical model that the authors of the present study propose could 
be further investigated quantitatively via a large-scale survey across industries to test whether it applies to dyads aside the hospital-pharmaceutical company relationship and beyond the confines of the pharmaceutical context.

An important theme that emerged from the present study was the role of Quality Improvement Plans in value-added initiatives within the hospital-pharmaceutical company relationship. Given that Quality Improvement Plans occupy a central role in hospital functioning, the role of QIPs should be further investigated. Future qualitative or quantitative research could explore the concept of "fit" between a hospital's QIP metrics and the internal competencies of a given supplier, as per Gosselin and Bauwen's (2006) congruence principle. Quantitative work could also focus on further elucidating the effectiveness of QIP individual quality dimensions on SAM initiatives.

\section{Limitations}

Research limitations do exist within this study. First, the dynamics of the hospital environment and politics within Canada are not necessarily reflected in other countries, and as such the conclusions drawn from this research cannot be applied directly to another hospital market without first investigating their similarities and differences. Second, the qualitative nature of this study renders the findings preliminary and exploratory; they cannot be regarded as conclusive and cannot be used to make generalizations to SAM models within the pharmaceutical industry. Additional (large-sample) quantitative research is, therefore, needed to test the generalizability of these findings to the pharmaceutical industry. In doing so, quantitative studies should work first on the development of scales for measuring the key concepts of the present study (a. the dimensions of 'customer-tailored value added initiatives' and 'relationship 
enhancers', and b. 'value co-creation' within the pharmaceutical company - hospital relationship) (see Figure 1 for the concepts). This can then enable a sound testing of the relationships between the two value co-creation dimensions, as well as their (individual and joint) impact on value co-creation within the pharmaceutical company - hospital dyad. Further, interviews were carried out only with customers in the dyadic, pharmaceutical company hospital, relationship. Thus the study addresses the perceptions and understandings of the hospital on the co-creation perspective. This is a limitation in the sense that it gives a one-sided understanding of the phenomenon, which could be more spherically understood if data were collected from both actors (i.e. customers and suppliers) in the relationship. The phenomenon that the study was set to investigate, leads to another key limitation. Since the research focused on eliciting insight on what the participants would like to have in regards to value-added relationship, the data collected reflect just thoughts and expectations and not actual experiences. The lack of experience of the phenomenon would have biased the actual emergent insights, and thus the credibility of the findings and the emergent theory may be at risk. Finally, the fact that each case reflects the meanings and understandings of two research participants, this may not essentially convey the full phenomenon within each case study. A more saturated understanding would be secured if more people could be interviewed from each participating hospital. At the same time, interviews could also take place at levels beyond the senior management. This could lead to diverse insight that would shed more light on the phenomenon at hand.

\section{References}

Abratt, R. and Kelly, P. M. (2002), “Customer-supplier partnerships: Perceptions of a successful key account management program”, Industrial Marketing Management, Vol 31 No 5, pp. 467-476.

Ahearne, M., Jelinek, R. and Jones, E. (2007), "Examining the effect of salesperson service behavior in a competitive context", Journal of the Academy of Marketing Science, Vol 35 No 4, pp. 603-616. 
ALHussan, F. B., AL-Husan, F. B. and Fletcher-Chen, C. C. Y. (2014), "Environmental factors influencing the management of key accounts in an Arab Middle Eastern context", Industrial Marketing Management, Vol 43 No 4, pp. 592-602.

Al-Husan, F. B. and Brennan, R. (2009), "Strategic account management in an emerging economy", Journal Of Business + Industrial Marketing, Vol 24 No 8, p. 611.

Alkhateeb, F. M., Khanfar, N. M. and Clauson, K. A. (2009), “Characteristics of physicians who frequently see pharmaceutical sales representatives", Journal of hospital marketing \& public relations, Vol 19 No 1, pp. 2-14.

Anderson, J. C. (1995), "Relationships in business markets: exchange episodes, value creation, and their empirical assessment”, Journal of the Academy of Marketing Science, Vol 23 No 4, pp. 346 350.

Anderson, J. C. and Narus, J. A. (1990), “A model of distributor firm and manufacturer firm working Partnerships", the Journal of Marketing, pp. 42-58.

Bacon, T. R. (1999), Selling to major accounts: tools, techniques, and practical solutions for the sales Manager, American Management Association, New York, NY.

Banerjee, S. and Dash, S. K. (2011), "Effectiveness of e-detailing as an innovative pharmaceutical marketing tool in emerging economies: Views of health care professionals of India", Journal of Medical Marketing: Device, Diagnostic and Pharmaceutical Marketing, Vol 11 No 3, pp. 204-214.

Berghman, L., Matthyssens, P. and Vandenbempt, K. (2006), "Building competences for new customer value creation: An exploratory study", Industrial marketing management, Vol 35 No 8, pp. 961-973.

Bryman, A. and Bell, E. (2015), Business research methods, Oxford university press.

Cannon, J. P. and Perreault Jr, W. D. (1999), "Buyer-seller relationships in business markets”, Journal of marketing research, pp. 439-460.

Chandler, A. D. (1990), Strategy and structure: Chapters in the history of the industrial enterprise (Vol. 120), MIT press.

Chimonas, S., Brennan, T. A. and Rothman, D. J. (2007), "Physicians and drug representatives: exploring the dynamics of the relationship", Journal of general internal medicine, Vol. 22, No. 2, pp. 184190.

DiMasi, J. A. and Grabowski, H. G. (2007), “The cost of biopharmaceutical R\&D: is biotech different?”, Managerial and Decision Economics, Vol. 28 No. 4-5, pp. 469-479.

Donaldson, L. (2001), The Contingency Theory of Organizations, Sage Publications, Thousand Oaks, CA.

Eisenhardt, K. M. and Graebner, M. E. (2007), “Theory building from cases: opportunities and challenges", Academy of management journal, Vol. 50 No. 1, pp. 25-32. 
Eisenhardt, K. M. (1989), “Building theories from case study research”, Academy of management review, Vol. 14 No. 4, pp. 532-550.

Georges, L. and Eggert, A. (2003), “Key account manager's role within the value creation process of collaborative relationships", Journal of Business-to-Business Marketing, Vol. 10 No. 4, pp. 1-22.

Gioia, D. A., Corley, K. G. and Hamilton, A. L. (2013), "Seeking qualitative rigor in inductive research notes on the Gioia methodology”, Organizational Research Methods, Vol. 16 No. 1, pp. $15-31$.

Gosselin, D. and Bauwen, G. (2006), "Strategic account management: customer value creation through customer alignment”, Journal of Business \& Industrial Marketing, Vol. 21 No. 6, pp. 376 - 385.

Gosselin, D. and Heene, A. (2003), “A competency-based analysis of account management: implications for a customer-focused organization", Journal of selling and Major Account Management, Vol. 5 No 1, pp. 11-31.

Gosselin, D.P. and Heene, A. (2005), "Strategic implications of a competence-based management approach to account management”, in Sanchez R. and Freiling I. (Eds.), Research in Competencebased Management - Vol. 1: A Focused Issue on the Marketing Process in Organizational Competence, Elsevier Science, Oxford, pp. 177-200.

Guenzi, P., Georges, L. and Pardo, C. (2009), "The impact of strategic account managers' behaviors on relational outcomes: An empirical study”, Industrial Marketing Management, Vol. 38 No. 3, pp. 300-311.

Hilsenrath P, (2011), "Health expenditure efficiency: implications for pharmaceutical marketing”, International Journal of Pharmaceutical and Healthcare Marketing, Vol. 5 No. 2, pp. 118 - 134.

Ivens, B. S. and Pardo, C. (2007), “Are key account relationships different? Empirical results on supplier strategies and customer reactions", Industrial Marketing Management, Vol. 36 No. 4, pp. 470-482.

Johannessen, J. A. and Olsen, B. (2010), “The future of value creation and innovations: Aspects of a theory of value creation and innovation in a global knowledge economy", International Journal of Information Management, Vol. 30 No. 6, pp. 502-511.

Lee, S. M., Olson, D. L. and Trimi, S. (2012), “Co-innovation: convergenomics, collaboration, and co-creation for organizational values", Management Decision, Vol. 50 No. 5, pp. 817-831.

Lepak, D. P., Smith, K. G. and Taylor, M. S. (2007), "Value creation and value capture: a multilevel perspective", Academy of management review, Vol. 32 No. 1, pp. 180-194.

Lewin, K. (1945), "The research center for group dynamics at Massachusetts Institute of Technology”, Sociometry, Vol. 8 No. 2, pp. 126-136.

Klein L, (2008), “Navigating restricted waters”, Medical Marketing and Media, Vol. 43 No. 4, pp. 49-53. 
Mackenzie, K. D. (2003), “Dynamic congruency”, in Rahim, M.A., Golembiewski, G.T. and MacKenzie K.D. (Eds.), Current Topics in Management, Volume 3, Transaction Publishers, pp. $19-42$.

Matthing, J., Sandén, B. and Edvardsson, B. (2004), "New service development: learning from and with customers", International Journal of Service Industry Management, Vol. 15 No 5, pp. 479498.

McDonald, M., Millman, T. and Rogers, B (1996), Key account management - Learning from supplier and customer perspective, Cranfield School of Management, Cranfield, UK.

McDonald, M., Millman, T. and Rogers, B. (1997), "Key account management: theory, practice and challenges", Journal of Marketing Management, Vol. 3 No. 13, pp. 737-57.

Miles, M. B. and Huberman, A. M. (1994), Qualitative data analysis: An expanded sourcebook. Sage.

Miles, R. E. and Snow, C. C. (1994), Fit, failure and the hall of fame: How companies succeed or fail, Free Press, New York, NY.

Miller, R. B., Heiman, S. E. and Tuleja, T. (1992), Successful large account management, Grand Central Publishing.

Moisander, J. and Valtonen, A. (2011), “Interpretive Marketing Research: Using Ethnography in Strategic Market Development", in Pennaloza, L., Toulouse, N. and Visconti L.M. (Eds), Marketing Management: A Cultural Perspective. Routledge

Montoya, R., Netzer, O. and Jedidi, K. (2010), "Dynamic allocation of pharmaceutical detailing and sampling for long-term profitability”, Marketing Science, Vol. 29 No. 5, pp. 909-924.

Morgan, B. (2010), “The Constitutionality of Restricting the Use of Prescriber-Identifiable Data in Pharmaceutical Detailing After Citizens United v. FEC", available at: http://nrs.harvard.edu/urn3:HUL.InstRepos:8822170

Morse, J. M. (2004), “Purposive sampling”, in Lewis-Beck, M., Bryman, A. and Liao, T. (Eds.), Encyclopedia of social science research methods, SAGE Publications, Thousand Oaks, CA, pp. 885-886.

Ojasalo J, (2001), "Key account management at company and individual levels in business-to-business relationships", Journal of Business \& Industrial Marketing, Vol. 16 No. 3, pp. 199-220.

Ontario Ministry of Health (2012), "Quality Improvement Plans”, available at: http://www.health.gov.on.ca/en/ms/ecfa/pro/updates/qualityimprove/update.aspx

Pardo, C., Henneberg, S. C., Mouzas, S. and Naude, P. (2006), "Unpicking the meaning of value in key account management”, European Journal of Marketing, Vol. 40 No. 11/12, pp. 1360-1374.

Patterson, J. (2008), "VIEWPOINT-Can Big Pharma Produce the Next Generation of Medicines? 
Patent pressures, changing disease profiles, and higher costs force companies to fight for the top", Pharmaceutical Technology, Vol. 32 No. 8, p. 114.

Payne, A. F., Storbacka, K. and Frow, P. (2008), "Managing the co-creation of value", Journal of the academy of marketing science, Vol. 36 No. 1, pp. 83-96.

Payne, D. J., Miller, L. F., Findlay, D., Anderson, J. and Marks, L. (2015), “Time for a change: addressing R\&D and commercialization challenges for antibacterials", Philosophical Transactions of the Royal Society of London B: Biological Sciences, Vol. 370, p. 1670.

Petit, M (2012), "Public funding of Pharmaceutical-company R\&D”, available at http://www.descanada.ca/anglais/public/pfund.htm

Piercy, N.F. and Lane N., (2006), "The hidden risks in strategic account management strategy”, Journal of Business Strategy, Vol. 27 No. 1, pp. 18 - 26.

Potts, S., Eberhard, D. and Wharton, K. (2015), Molecular Histopathology and Tissue Biomarkers in Drug and Diagnostic Development, New York, Springer.

Prahalad, C. K. (2004), "The co-creation of value-Invited commentary”, Journal of Marketing, Vol. 68 No. 1, p. 23.

Prahalad, C. K. and Ramaswamy, V. (2004), "Co-creation experiences: The next practice in value creation", Journal of interactive marketing, Vol. 18 No. 3, pp. 5-14.

Ramaswamy, V. (2011), "It's about human experiences... and beyond, to co-creation", Industrial Marketing Management, Vol. 40 No. 2, pp. 195-196.

Rubin P, (2004), "Pharmaceutical marketing: medical and industry biases", Journal of Pharmaceutical Finance, Economics and Policy, Vol. 13 No. 2, pp. 65-79.

Sillup G. and Porth, S. (2008), "Ethical issues in the pharmaceutical industry: an analysis of US newspapers", International Journal of Pharmaceutical and Healthcare Marketing, Vol. 2 No. 3, pp. $163-180$.

Smith B, (2009), "Myth, reality and requirements in pharmaceutical key account management", Journal of Medical Marketing, Vol. 9 No. 2, pp. 89-95.

Storbacka, K. (2012), "Strategic account management programs: alignment of design elements and management practices", Journal of Business \& Industrial Marketing, Vol. 27 No. 4, pp. 259-274.

Sullivan, U. Y., Peterson, R. M. and Krishnan, V. (2012), "Value creation and firm sales performance: The mediating roles of strategic account management and relationship perception", Industrial Marketing Management, Vol. 41 No. 1, pp. 166-173.

TUFTS Center for the Study of Drug Development (2014), "How the Tufts Center for the Study of Drug

Development pegged the cost of a new drug at $\$ 2.6$ billion", available at http://csdd.tufts.edu/files/uploads/cost_study_backgrounder.pdf 
Vanderveer R, (2002), “The new micromarketing: Looking at the practice as an account to be managed, rather than the doctor as a target to be hit”, Journal of Medical Marketing, Vol. 2 No. 3, pp. 200205.

Vargo, S. L., Maglio, P. P. and Akaka, M. A. (2008), “On value and value co-creation: A service systems and service logic perspective”, European management journal, Vol. 26 No. 3, pp. 145-152.

Vargo, S. L. and Lusch, R. F. (2008), "Service-dominant logic: continuing the evolution", Journal of the Academy of marketing Science, Vol. 36 No. 1, pp. 1-10.

Wartenberg, F. and Gores, M. (2008), "New model pharma", Pharmaceutical Executive Europe, February, pp. 9-14

Weitz, B. and Bradford, K. (1999), "Personal selling and sales management: a relationship marketing experience", Journal of the Academy of Marketing Science, Vol. 27 No. 2, pp. 241-254.

Wenzel, M., Henne, N. and Zöllner, Y. (2014), "Beyond the pill-the move towards value-added services in the pharmaceutical industry", Journal of Medical Marketing, pp. 1-8.

Workman, J. P., Homburg, C. and Jensen, O. (2003), “Intraorganizational determinants of key account management effectiveness", Journal of the Academy of Marketing Science, Vol. 31 No. 1, pp. 3-21.

Yin, R. K. (2013), Case study research: Design and methods, Sage publications. 
Table 1 - Characteristics of the SAM approach

\begin{tabular}{|c|c|c|c|c|}
\hline$\gamma$ & Emphasis & $\begin{array}{c}\text { Equally } \\
\text { emphasized }\end{array}$ & Emphasis & \\
\hline $\begin{array}{l}\text { Transactional } \\
\text { marketing/ short- } \\
\text { term approach }\end{array}$ & & & * & $\begin{array}{l}\text { Relationship } \\
\text { marketing/ Long- } \\
\text { term approach } \\
\text { Operational }\end{array}$ \\
\hline Strategic & & $*$ & & \\
\hline $\begin{array}{l}\text { Theoretical/ } \\
\text { descriptive }\end{array}$ & & $*$ & & $\begin{array}{l}\text { Managerial/ } \\
\text { normative }\end{array}$ \\
\hline $\begin{array}{l}\text { Consumer } \\
\text { market }\end{array}$ & & & * & $\begin{array}{l}\text { Business-to- } \\
\text { business market }\end{array}$ \\
\hline Goods & & * & & Services \\
\hline $\begin{array}{l}\text { Goals: } \\
\text { Profitability \& } \\
\text { Shareholder Value }\end{array}$ & 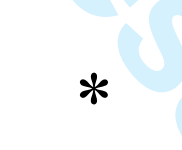 & & & $\begin{array}{lr}\text { Goals: } & \text { Sales } \\
\text { volume, } & \text { market } \\
\text { share, } & \text { margins etc }\end{array}$ \\
\hline
\end{tabular}

Source: Ojasalo, 2011, p. 209 
Table 2-Profiles of Cases and research participants






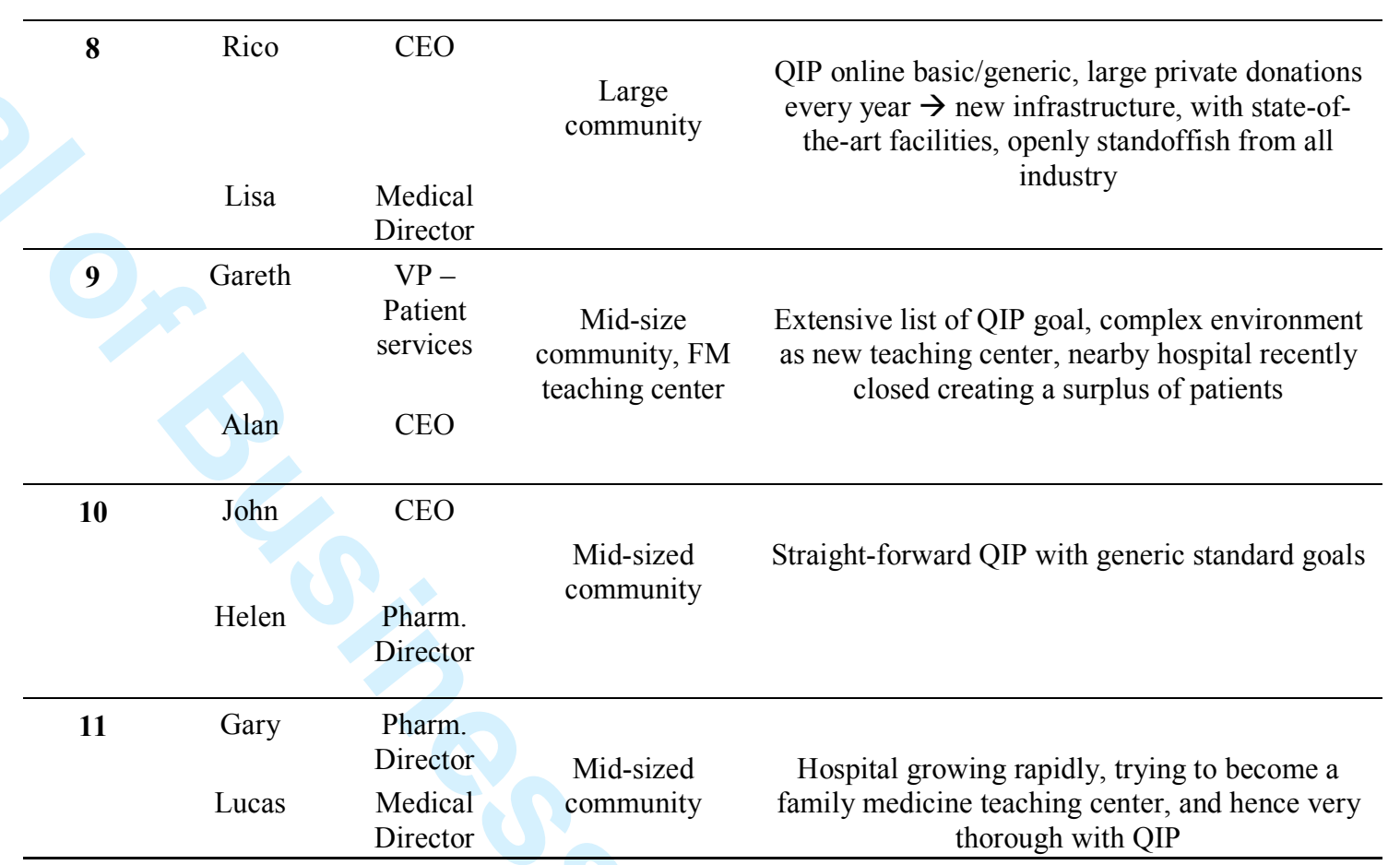


Figure 1-SAM and the hospital-pharmaceutical company relationship: A Cycle of Value Co-Creation

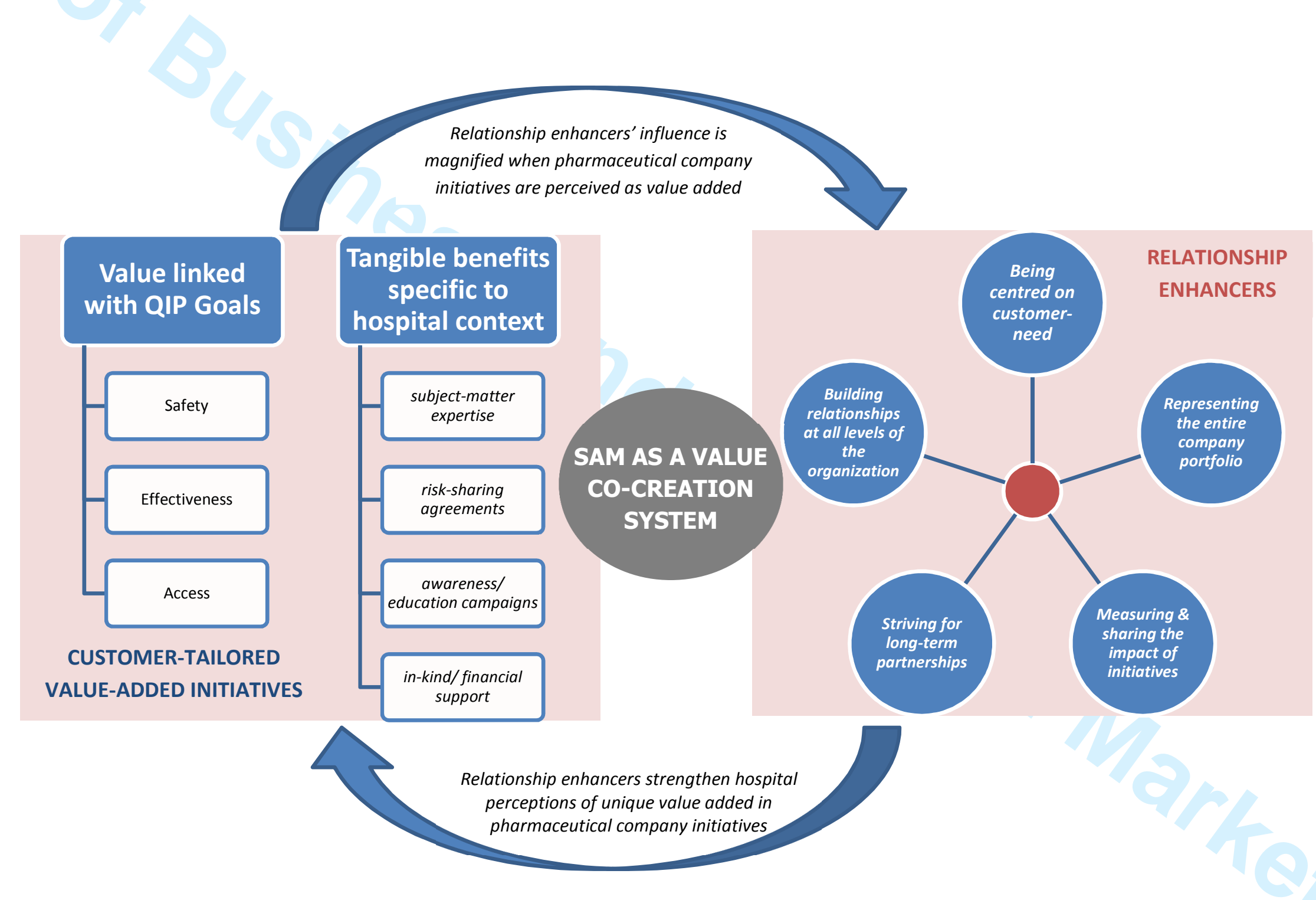

http://mc.manuscriptcentral.com/jbim 